\title{
Time in the stair-climbing test as a predictor of thoracotomy postoperative complications
}

\author{
Alexandre Ricardo Pepe Ambrozin, PhD, ${ }^{a}$ Daniele Cristina Cataneo, $\mathrm{MD}, \mathrm{PhD},{ }^{\mathrm{b}}$ \\ Karine Aparecida Arruda, MA, ${ }^{a}$ and Antônio José Maria Cataneo, $\mathrm{MD}, \mathrm{PhD}^{\mathrm{b}}$
}

Objectives: The stair-climbing test as measured in meters or number of steps has been proposed to predict the risk of postoperative complications. The study objective was to determine whether the stair-climbing time can predict the risk of postoperative complications.

\begin{abstract}
Methods: Patients aged more than 18 years with a recommendation of thoracotomy for lung resection were included in the study. Spirometry was performed according to the criteria by the American Thoracic Society. The stair-climbing test was performed on shaded stairs with a total of $12.16 \mathrm{~m}$ in height, and the stair-climbing time in seconds elapsed during the climb of the total height was measured. The accuracy test was applied to obtain stair-climbing time predictive values, and the receiver operating characteristic curve was calculated. Variables were tested for association with postoperative cardiopulmonary complications using the Student $t$ test for independent populations, the Mann-Whitney test, and the chi-square or Fisher exact test. Logistic regression analysis was performed.
\end{abstract}

Results: Ninety-eight patients were evaluated. Of these, 27 showed postoperative complications. Differences were found between the groups for age and attributes obtained from the stair-climbing test. The cutoff point for stair-climbing time obtained from the receiver operating characteristic curve was 37.5 seconds. No differences were found between the groups for forced expiratory volume in 1 second. In the logistic regression, stair-climbing time was the only variable associated with postoperative complications, suggesting that the risk of postoperative complications increases with increased stair-climbing time.

Conclusions: The only variable showing association with complications, according to multivariate analysis, was stair-climbing time. (J Thorac Cardiovasc Surg 2013;145:1093-7)

Postoperative complications (POCs) occur in $6.8 \%$ to $30 \%$ of individuals who undergo noncardiac thoracic surgery. ${ }^{1}$ Because POCs increase morbidity and mortality, and, secondarily, the duration and cost of hospitalization, it is important to identify patients who may have such complications to reduce their risk by means of preoperative preparation. However, to date, no agreement has been reached in regard to the best test to stratify surgical risk. ${ }^{2}$

The cardiopulmonary stress experienced by patients in the intraoperative and postoperative periods of thoracic surgery is responsible for POCs. Cardiopulmonary stress is complicated to measure and sometimes makes the decision to perform surgery difficult because of the uncertainty of whether the patient can withstand the procedure. However,

\footnotetext{
From the Program on General Basis of Surgery, ${ }^{\mathrm{a}}$ and Division of Thoracic Surgery, ${ }^{\mathrm{b}}$ Department of Surgery, Botucatu School of Medicine, São Paulo State University, UNESP, São Paulo, Brazil.

Disclosures: Authors have nothing to disclose with regard to commercial support.

Received for publication May 15, 2012; revisions received Aug 3, 2012; accepted for publication Sept 4, 2012; available ahead of print Oct 24, 2012.

Address for reprints: Daniele Cristina Cataneo, MD, PhD, Division of Thoracic Surgery, Department of Surgery, Botucatu School of Medicine, São Paulo State

University, UNESP, São Paulo, Brazil, CEP 18.618-970, Botucatu SP, Brazil

(E-mail: dcataneo@fmb.unesp.br).

$0022-5223 / \$ 36.00$

Copyright (C) 2013 by The American Association for Thoracic Surgery

http://dx.doi.org/10.1016/j.jtcvs.2012.09.001
}

few studies suggest that cardiorespiratory exercise tests can be applied for this purpose. ${ }^{3}$

The exercise test has been used in the last few years in patients who are eligible for thoracotomy. Of the variables obtained in the ergospirometric test, maximal oxygen uptake $\left(\mathrm{VO}_{2}\right)$ is considered to be the gold standard in surgical risk and postoperative prognosis prediction. ${ }^{4}$ In the past, diffusing capacity of carbon monoxide also was considered the best predictor of postoperative pulmonary complications in lung resection, ${ }^{5}$ but its use in the preoperative evaluation of patients undergoing lung resection has not been routine. ${ }^{6}$

$\mathrm{VO}_{2}$ assessment by means of ergospirometric tests is costly and depends on specific equipment, an appropriate site, and properly trained staff. Diffusing capacity of carbon monoxide assessment also depends on specific equipment. However, many hospitals do not have such equipment, and thus other tests are used to predict surgical risk, among which is the stair-climbing test (SCT). ${ }^{7}$

There is a correlation between the results of $\mathrm{VO}_{2}$ obtained on the ergospirometric test and various parameters obtained from the SCT, such as the estimated $\mathrm{VO}_{2}$, height achieved, ${ }^{8,9}$ testing speed, ${ }^{10}$ desaturation during its performance, ${ }^{11}$ and time spent to climb the steps. ${ }^{12,13}$

As described in the literature, height is the main variable in SCT, not taking into account the time spent to reach it. On 


\section{Abbreviations and Acronyms \\ $\mathrm{FEV}_{1}=$ forced expiratory volume in 1 second \\ $\mathrm{PaCO}_{2}=$ arterial pressure of carbon dioxide \\ $\mathrm{POC}=$ postoperative complication \\ ROC $=$ receiver operating characteristic \\ $\mathrm{SCT}=$ stair-climbing test \\ $\mathrm{SCt}=$ stair-climbing time \\ $\mathrm{VO}_{2}=$ maximal oxygen uptake}

the basis of the findings by Cataneo and Cataneo, ${ }^{12}$ our study proposes the use of stair-climbing time ( $\mathrm{SCt}$ ) as a predictor of POCs. Therefore, the present study aimed to determine whether the time for climbing all the steps during the SCT can be a predictor of post-thoracotomy complications and whether other tests, such as forced expiratory volume in 1 second $\left(\mathrm{FEV}_{1}\right)$ of spirometry, are capable of predicting POCs.

\section{MATERIALS AND METHODS Studied Population}

Inpatients from the Thoracic Surgery Ward of the Botucatu School of Medicine University Hospital, São Paulo State University, UNESP, were studied from June 2006 to July 2009. This project was approved by the institution's research ethics committee (REB398/06).

Patients aged more than 18 years with a recommendation of thoracotomy for major lung resection were included in the study. Patients with a history of unstable angina, myocardial infarction less than 3 months before surgery, decompensated heart failure, decompensated obstructive pulmonary disease, difficulties in walking (muscle skeletal, neurologic, or vascular alterations), and resting pulse rate greater than 120 beats/min were excluded. ${ }^{9}$

\section{Measurements}

Spirometry was performed according to the criteria by the American Thoracic Society ${ }^{14}$ on a Medgraphics Pulmonary Function System 1070 spirometer (Medical Graphics Corp, St Paul, Minn). The FEV $_{1}$ value was obtained in liters and predicted percentage.

The SCT was performed on shaded stairs with a 30-degree incline, which consisted of 6 flights with 12 steps each, thus totaling 72 steps. Each step measured $16.9 \mathrm{~cm}$, with a total of $12.16 \mathrm{~m}$ in height. The patient was advised to climb all the steps at the shortest possible time with verbal stimulation standardized at every flight. Between the stair flights, the patient needed to take 2 or 3 steps, where speed should be maintained. The test would be interrupted by fatigue, intense dyspnea, thoracic pain, or exhaustion. The time in seconds that elapsed during the climb of the total height was denominated as the SCt. Stair-climbing power $(\mathrm{P})$ was calculated as $\mathrm{P}=\mathrm{m} \times \mathrm{g} \times \mathrm{h} / \mathrm{SCt}$, where $\mathrm{m}$ is the patient's body mass in kilograms, $g$ is the acceleration of gravity $\left(9.8 \mathrm{~m} / \mathrm{s}^{2}\right), \mathrm{h}$ is the total height of the stairs in meters $(12.16 \mathrm{~m})$, and $\mathrm{SCt}$ is the time spent to climb all the steps. The $\mathrm{VO}_{2}$ was estimated from SCt $\left(\mathrm{VO}_{2} \mathrm{t}=43.06-0.4 \times \mathrm{SCt}\right)$ and $\mathrm{P}\left(\mathrm{VO}_{2} \mathrm{P}=15.9+0.048 \times \mathrm{P}\right) .{ }^{13}$ All intraoperative complications and surgical duration were recorded. In the postoperative period, patients were followed up daily, and cardiopulmonary complications were recorded. The following events unrelated to the surgical technique were considered to be complications ${ }^{11}$ : myocardial infarction, congestive heart failure, arrhythmia, reintubation, orotracheal intubation for more than 24 hours after surgery, pneumonia, atelectasis requiring bronchoscopic aspiration, pulmonary thromboembolism, arterial pressure of carbon dioxide $\left(\mathrm{PaCO}_{2}\right)$ of
$50 \mathrm{~mm} \mathrm{Hg}$ or more in patients who had normal $\mathrm{PaCO}_{2}$ preoperatively, acute pulmonary edema, and death. Postoperative hospitalization time and the time of maintenance of a thoracic drainage also were recorded.

\section{Statistical Analysis}

Patients were divided into 2 groups according to the absence (no POC group) or presence (POC group) of POCs. To define the cutoff points that could stratify surgical risk, SCt was categorized according to time as follows: less than 30 seconds, 30 to 50 seconds, and more than 50 seconds. Through these accuracy tests, predictive values for different SCt cutoff points were estimated. Two times ( 30 and 50 seconds) were selected to optimize the selection criteria: Patients who were able to climb all the steps in less than 30 seconds would have a low probability to develop POCs, and patients who took more than 50 seconds to climb all the steps would have a higher probability to develop POCs. SCt categorization for statistical analyses was based on previous studies. ${ }^{9,12,13}$ The receiver operating characteristic (ROC) curve also was applied for SCt. Such a curve was constructed on the basis of the variable that classifies the individuals with and without complications, and then showed through the other variable (SCt) the cutoff point by sensitivity and specificity analyses. Independent variables were tested for association with POCs (dependent variable). These variables initially underwent univariate analysis and then multivariate analysis (logistic regression). The continuous variables with normal distribution were compared by the Student $t$ test for independent populations, and those that did not show normal distribution were compared by the Mann-Whitney test. The categoric variables were compared by the chi-square or Fisher exact test.

To test the association of variables with the presence of complications, logistic regression (full model) was performed. The dependent variable was the presence of complications, and the independent continuous variables were age, $\mathrm{FEV}_{1}$, and SCt. Statistical analyses were performed by using SAS version 9.2 (SAS Institute Inc, Cary, NC).

\section{RESULTS}

Ninety-eight patients (60 male) were evaluated. Seventyone patients (72.4\%) had no POCs (no POC group), and 27 patients $(27.6 \%)$ had POCs (POC group). Of the several complications found in the POC group, 15 patients had only 1 complication and 12 patients had 2 or more complications. Eleven patients had atelectasis, 10 patients had pneumonia, 7 patients had prolonged orotracheal intubation, 5 patients had arrhythmia, 5 patients had $\mathrm{PaCO}_{2}$ greater than $50 \mathrm{~mm} \mathrm{Hg}, 2$ patients had congestive heart failure, 2 patients were reintubated, 2 patients died, 1 patient had acute myocardial infarction, 1 patient had pulmonary thromboembolism, and 1 patient had acute pulmonary edema. Patients' characteristics are shown in Table 1.

By stratifying the patients according to $\mathrm{SCt}$, it is observed that the lower the SCt, the lower the percentage of patients with complications. Of the patients who took less than 30 seconds to climb the stairs, $14 \%$ had POCs, increasing to $26 \%$ for those who took 30 to 50 seconds and to $60 \%$ for those who took 50 seconds or more to climb the stairs (Table 2). The rate of complications for patients who took 50 seconds or more to climb the stairs is 4.3 -fold that of those who took less than 30 seconds (9/15 vs 4/29).

By applying the accuracy test for different cutoff points, it is observed that a patient's probability to show 
TABLE 1. Characteristics of the studied patients in mean \pm standard deviation values

\begin{tabular}{lcccc}
\hline \multicolumn{1}{c}{ Variable } & $\begin{array}{c}\text { No POC group } \\
\text { mean } \pm \text { SD }\end{array}$ & $\begin{array}{c}\text { POC group } \\
\text { mean } \pm \text { SD }\end{array}$ & $\begin{array}{c}\text { Total } \\
\text { mean } \pm \text { SD }\end{array}$ & $\begin{array}{c}P \\
\text { value }\end{array}$ \\
\hline Age $(\mathrm{y})$ & $50.5 \pm 17.4$ & $58.4 \pm 15.3$ & $52.7 \pm 17.2$ & .04 \\
$\mathrm{BMI}\left(\mathrm{kg} / \mathrm{m}^{2}\right)$ & $25.0 \pm 5.0$ & $25.5 \pm 4.9$ & $25.1 \pm 5.0$ & .62 \\
$\mathrm{FEV}_{1}(\mathrm{~L})$ & $2.4 \pm 0.8$ & $2.1 \pm 0.6$ & $2.3 \pm 0.8$ & .08 \\
$\mathrm{FEV}_{1}(\%)$ & $85.3 \pm 26.1$ & $72.0 \pm 24.6$ & $84.3 \pm 25.6$ & .55 \\
$\mathrm{SCt}(\mathrm{s})$ & $35.8 \pm 12.8$ & $46.6 \pm 17.4$ & $38.7 \pm 14.9$ & .005 \\
$\mathrm{P}(\mathrm{w})$ & $250.8 \pm 94.8$ & $193.4 \pm 72.7$ & $235.0 \pm 92.5$ & .005 \\
$\mathrm{VO}_{2} \mathrm{t}(\mathrm{mL} / \mathrm{kg} / \mathrm{min})$ & $28.8 \pm 5.1$ & $24.4 \pm 7.0$ & $27.6 \pm 6.0$ & .005 \\
$\mathrm{VO}_{2} \mathrm{P}(\mathrm{mL} / \mathrm{kg} / \mathrm{min})$ & $27.9 \pm 4.5$ & $25.2 \pm 3.5$ & $27.2 \pm 4.4$ & .005 \\
$\left.\mathrm{Smoking}(\mathrm{pack}-\mathrm{y})^{2}\right)$ & $21.7 \pm 25.9$ & $25.4 \pm 26.4$ & $22.8 \pm 25.9$ & .53
\end{tabular}

$P O C$, Postoperative complication; $S D$, standard deviation; $B M I$, body mass index; $F E V_{1}$, forced expiratory volume in 1 second; $S C t$, stair-climbing time; $P(w)$, power expressed in watts; $V O_{2} t$, oxygen consumption estimated from $\mathrm{SCt} ; \mathrm{VO}_{2} P$, oxygen consumption estimated from $\mathrm{P}$.

complications if he/she climbs the stairs in less than $50 \mathrm{sec}-$ onds is $60 \%$, but if he/she climbs the stairs in less than 30 seconds, the probability decreases to $33.3 \%$ (Table 3 ). The cutoff point obtained by the ROC curve for SCt in this group of patients was 37.5 seconds (Figure 1).

There was no difference between the groups in occasional intraoperative complications or surgery duration (no POC group: $4.6 \pm 1.9$ hours; POC group: $5.0 \pm 2.1$ hours, $P=.49$ ). No statistically significant association was found between the presence of complications and the surgery type (lobectomy or pneumonectomy) $(P=.52)$.

Patients in the POC group remained drained for $6.6 \pm 3.8$ days, and patients in the no POC group remained drained for $4.3 \pm 1.9$ days $(P=.005)$. Postoperative hospitalization time was $5.6 \pm 2.5$ days in the no POC group and $13.7 \pm 12.7$ days in the POC group $(P=.003)$.

By multivariate analysis, the only significant variable showing an association with POCs was SCt (odds ratio, 1.041; 95\% confidence interval, 1.005-1.079) (Table 4). The risk of POCs increases $4 \%$ per second to climb the stairs.

\section{DISCUSSION}

The spirometric variables did not differ between groups, probably because both had capacities and volumes within or close to normality, and perhaps for that reason $\mathrm{FEV}_{1}$ was not able to stratify the risk group. In other studies ${ }^{15,16}$ on patients undergoing thoracic surgery, there was no difference in spirometric variables when comparing the groups with and without POCs. In a previous study, when

TABLE 2. Cardiopulmonary complications stratified by time in stairclimbing test

\begin{tabular}{clll}
\hline SCt & $\begin{array}{c}<\mathbf{3 0} \mathrm{s} \\
(\mathbf{n}=\mathbf{2 9})\end{array}$ & $\begin{array}{c}\mathbf{3 0 - 5 0} \mathrm{s} \\
(\mathbf{n}=\mathbf{5 4})\end{array}$ & $\begin{array}{c}>\mathbf{5 0} \mathrm{s} \\
(\mathbf{n}=\mathbf{1 5})\end{array}$ \\
\hline Cardiopulmonary complications n $(\%)$ & $4(14)$ & $14(26)$ & $9(60)$ \\
\hline
\end{tabular}

$\overline{S C t}$, Stair-climbing time. $P=.0047$.
TABLE 3. Predictive positive and negative values for different stairclimbing time cutoff points

\begin{tabular}{lcc}
\hline SCt (s) & PPV (\%) & NPV (5) \\
\hline 30 & 33.3 & 86.2 \\
50 & 60.0 & 78.3 \\
\hline
\end{tabular}

$S C t$, Stair-climbing time; $P P V$, positive predictive value; $N P V$, negative predictive value.

our group measured the accuracy of predictive tests for surgical risk using $\mathrm{VO}_{2}$ as a gold standard, ${ }^{12,13}$ it was observed that $\mathrm{FEV}_{1}$ both in liters and in predicted percentage showed low sensitivity and specificity to predict $\mathrm{VO}_{2}$ values by not stratifying compromised patients, but only excluding those without clinical conditions for extensive resections.

Spirometry variables were close to normality in this population, showing that patients' pulmonary conditions were good despite their respiratory comorbidities and smoking. The American College of Chest Physicians establishes, as one of the guidelines for use of spirometry in the pulmonary resection postoperative period, that patients with an $\mathrm{FEV}_{1}$ greater than $1.5 \mathrm{~L}$ can undergo lobectomy, and those with an $\mathrm{FEV}_{1}$ greater than $2 \mathrm{~L}$ can undergo pneumonectomy, without the need of other tests, with level of evidence 1C. ${ }^{17}$ In the studied population of 59 patients with $\mathrm{FEV}_{1}$ greater than $2 \mathrm{~L}, 14$ had POCs, thus showing that spirometry alone is not capable of predicting risk and that other evaluations are required, because even patients with good pulmonary function and small resections had POCs. Likewise, another study ${ }^{18}$ found a complication rate after thoracotomy as high as the one presented in this study in patients who had normal $\mathrm{FEV}_{1}(83.8 \%$ on average). When just elderly patients were included, even if they had Charlson Comorbidity index zero, the POCs were greater than $50 \% .{ }^{19}$ Since the mid-20th century, studies have shown that mortality is

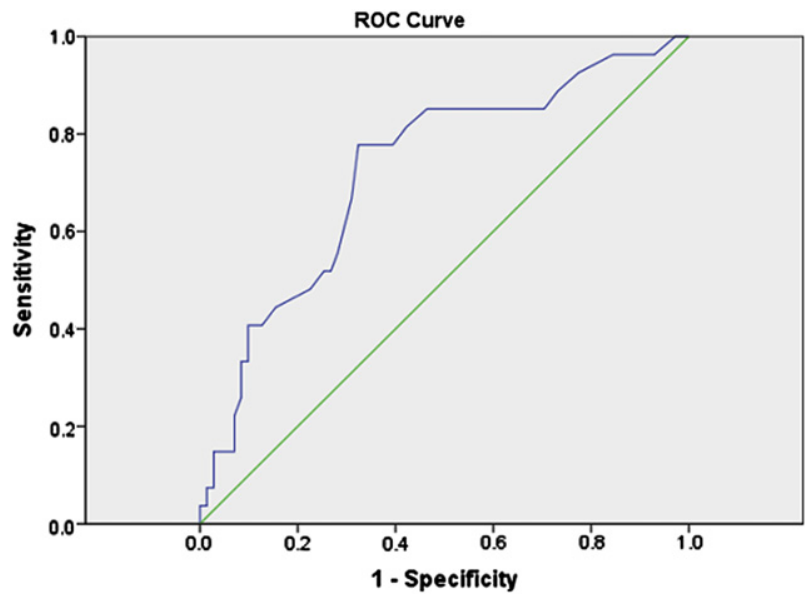

FIGURE 1. ROC curve for stair-climbing time sensitivity (true positive) and $1-$ specificity (false positive). Cutoff point $=37.5$ seconds (sensitivity $=67 \%$, specificity $=69 \%$ ), area $=0.725$, standard deviation $=0.058$, and $P=.001 . R O C$, Receiver operating characteristic. 
TABLE 4. Logistic regression

\begin{tabular}{lcccc}
\hline Variable & Estimation & SE & $\boldsymbol{P}$ value & OR $(\mathbf{9 5} \% \mathbf{C I})$ \\
\hline Constant & -2.254 & 1.475 & .127 & 0.105 \\
Age (y) & 0.006 & 0.018 & .727 & $1.006(0.971-1.043)$ \\
$\mathrm{FEV}_{1}(\mathrm{~L})$ & -0.304 & 0.352 & .388 & $0.738(0.370-1.472)$ \\
$\mathrm{SCt}(\mathrm{s})$ & 0.040 & 0.018 & .027 & $1.041(1.005-1.079)$ \\
\hline
\end{tabular}

Dependent variable: POCs. Independent variables: age, $\mathrm{FEV}_{1}$, and SCt. $S E$, Standard error; $O R$, odds ratio; $C I$, confidence interval; $F E V_{l}$, forced expiratory volume in 1 second; $S C t$, stair-climbing time.

correlated to the number of steps that the patient is able to climb during the $\mathrm{SCT}^{20,21}$ Therefore, SCT can be complementary to spirometry. ${ }^{22}$ Although the SCT is extensively used, its performance has not been standardized; most literature data show the correlation between the height reached and POCs. Nevertheless, tests are performed on stairs of different sizes, where patients are advised to take their time during climbing and to climb as far as they can without stimulation, which always hinders comparisons.

Because the SCT has not been standardized, there is no agreement in the literature in regard to the minimum height to be reached by patients with complications, and it may range from $6.42 \mathrm{~m}^{16}$ to $16.23 \mathrm{~m}^{22}$ However, a recent study showed that patients who reached a height less than $12 \mathrm{~m}$ during the SCT had higher mortality and POCs. ${ }^{11}$ Nevertheless, height as an isolated variable is not significant, because an individual who takes 40 seconds to reach $12 \mathrm{~m}$ is different from one who takes 120 seconds.

A minimum height and the performance of verbal stimulation are still objects of investigation, although we believe that such variables will contribute to SCT standardization. The use of stair height alone may be a limitation in some hospitals, for example, in the Botucatu School of Medicine Hospital, which is mostly a horizontal hospital. However, according to the literature, high heights are not necessary, because $12 \mathrm{~m}$ was enough to identify complication risk. In a previous study performed by the current authors, ${ }^{12}$ the use of stairs with a fixed height of $12.16 \mathrm{~m}$ was standardized in the hospital. On those stairs, all the steps should be climbed at the shortest time possible with verbal stimulation at each flight and using the time as the only variable. With this test, it was possible to accurately measure the power and the work performed during the climb, which would be proportional to the individual's functional capacity. Such standardization also allows for reproducing the test on any stairs with a minimum height of $12 \mathrm{~m}$, which also can be compared with procedures in studies using speed, ${ }^{10}$ as shown by Cataneo and colleagues. ${ }^{13}$

The inclusion of the $\mathrm{SCt}$ as a variable is also important because it showed high correlation with the $\mathrm{VO}_{2}$ obtained in ergospirometry, ${ }^{12,13}$ thus allowing the estimated $\mathrm{VO}_{2}$ to be obtained.

The SCt in the POC group was longer than in the no POC group, and as SCt decreased, so did the number of complications; in addition, the complication rate in those taking less than 30 seconds to climb all the steps was 4.3-fold less frequent than in those taking 50 seconds. A similar result was found by Brunelli and colleagues ${ }^{11}$ for the height reached in the SCT, and not time, thus showing that the patients who climbed less than $12 \mathrm{~m}$ had twice as many complications as those who climbed more than $22 \mathrm{~m}$.

The cutoff point for SCt to separate the groups found through the ROC curve was rather reduced, because the curve separates patients with and without complications in a population believed to have good physical performance. By using accuracy tests, previous studies ${ }^{12,13}$ observed that patients taking less than 40 seconds to climb all the steps were highly likely to show $\mathrm{VO}_{2}$ greater than $25 \mathrm{~mL} / \mathrm{kg} /$ min, which confirmed their good physical performance.

\section{CONCLUSIONS}

Although the evaluated patients were in good physical condition and the studied groups were similar, the SCt could stratify them, indicating that it would be useful and necessary to invest in prospective multicenter studies to standardize and validate the SCT for application in the preoperative period, because this is an inexpensive test that can be performed in most hospitals, as opposed to ergospirometry. In addition, such a test can identify alterations even in individuals with good physical performance, in whom $\mathrm{FEV}_{1}$ in liters and predicted percentage could not.

The authors thank Patrícia Pintor dos Reis, PhD, from the Department of Surgery and Orthopedics of the São Paulo State University, for the English language review.

\section{References}

1. Sweitzer BJ, Smetana GW. Identification and evaluation of the patient with lung disease. Med Clin North Am. 2009;93:1017-30.

2. Matsuoka H, Nishio W, Sakamoto T, Harada H, Tsubota N. Prediction of morbidity after lung resection with risk factors using treadmill exercise test. Eur J Cardiothorac Surg. 2004;26:480-2.

3. Win T, Jackson A, Sharples L, Groves AM, Wells FC, Ritchie AJ, et al. Cardiopulmonary exercise test and lung cancer surgical outcome. Chest. 2005;127: 1159-65.

4. Wyser C, Stulz P, Solèr M, Tamm M, Müller-Brand J, Habicht J, et al. Prospective evaluation of an algorithm for the functional assessment of lung resection candidates. Am J Respir Crit Care Med. 1999;159:1450-6.

5. Ferguson MK, Little L, Rizzo L, Popovich J, Glonek GF, Leff A, et al. Diffusing capacity predicts morbidity and mortality after pulmonary resection. $J$ Thorac Surg. 1988;96:894-900.

6. Berrisford R, Brunelli A, Rocco G, Treasure T, Utley M, Audit and guidelines committee of the European Society of Thoracic Surgeons, European Association of Cardiothoracic Surgeons. The European Thoracic Surgery Database project: modelling the risk of in-hospital death following lung resection. Eur J Cardiothorac Surg. 2005;28:306-11.

7. Brunelli A, Socci L, Refai M, Salati M, Xiumé F, Sabbatini A. Quality of life before and after major lung resection for lung cancer: a prospective follow-up analysis. Ann Thorac Surg. 2007;84:410-6.

8. Benzo R, Kelley GA, Recchi L, Hofman A, Sciurba F. Complications of lung resection and exercise capacity: a meta-analysis. Respir Med. 2007;101:1790-7.

9. Brunelli A, Refai M, Xiumé F, Salati M, Sciarra V, Socci L, et al. Performance at symptom-limited stair-climbing test is associated with increased cardiopulmonary complications, mortality and costs major lung resection. Ann Thorac Surg. 2008;86:240-8. 
10. Koegelenberg CF, Diacon AH, Irani S, Bolliger CT. Stair climbing in the functional assessment of lung resection candidates. Respiration. 2008;75:374-9.

11. Brunelli A, Refai M, Xiumé F, Salati M, Marasco R, Sciarra V, et al. Oxygen desaturation during maximal stair-climbing test and postoperative complications after major lung resections. Eur J Cardiothorac Surg. 2008;33:77-82.

12. Cataneo D, Cataneo AJM. Accuracy of the stair-climbing test using maximal oxygen uptake as the gold standard. J Bras Pneumol. 2007;33:128-33.

13. Cataneo DC, Kobayasi S, Carvalho LR, Paccanaro RC, Cataneo AJ. Accuracy of six minute walk test, stair test and spirometry using maximal oxygen uptake as gold standard. Acta Cir Bras. 2010;25:194-200.

14. American Thoracic Society. Standardization of spirometry. Am J Respir Crit Care Med. 1995;152:2185-98.

15. Stéphan F, Boucheseiche S, Hollande J, Flahault A, Cheffi A, Bazelly B, et al. Pulmonary complications following lung resection: a comprehensive analysis of incidence and possible risk factors. Chest. 2000;118:1263-70.

16. Girish M, Trayner E Jr, Dammann O, Pinto-Plata V, Celli B. Symptom-limited stair climbing as a predictor of postoperative cardiopulmonary complications after high-risk surgery. Chest. 2001;120:1147-51.
17. Colice GL, Shafazand S, Griffin JP, Keenan R, Bolliger CT, American College of Chest Physicians. Physiologic evaluation of the patient with lung cancer being considered for resectional surgery: ACCP evidence-based clinical practice guidelines (2nd Edition). Chest. 2007;132:161-77.

18. Paul S, Altorki NK, Sheng S, Lee PC, Harpole DH, Onaitis MW, et al. Thoracoscopic lobectomy is associated with lower morbidity than open lobectomy: a propensity-matched analysis from the STS database. J Thorac Cardiovasc Surg. 2010;139:366-78

19. Rueth NM, Parsons HM, Habermann EB, Groth SS, Virnig BA, Tuttle TM, et al Surgical treatment of lung cancer: predicting postoperative morbidity in the elderly population. J Thorac Cardiovasc Surg. 2012;143:1314-23.

20. Souders CR. Clinical evaluation of the patient for thoracic surgery. Surg Clin North Am. 1961;41:545-56.

21. Olsen GN. Preoperative physiology and lung resection. Scan? Exercise? Both? Chest. 1992;101:300-1.

22. Brunelli A, Monteverde M, Al Refai M, Fianchini A. Stair climbing test as a predictor of cardiopulmonary complications after pulmonary lobectomy in the elderly. Ann Thorac Surg. 2004;77:266-70. 